\title{
Influence of photoperiod on the development of diapause in larvae and its cost for individuals of a univoltine population of Dendrolimus punctatus (Lepidoptera: Lasiocampidae)
}

\author{
Ju-PING ZENG ${ }^{1,2}$, Yong WANG ${ }^{3}$ and XING-PING LIU ${ }^{1}$ \\ ${ }^{1}$ College of Forestry, Jiangxi Agricultural University, Zhimin Road 1225, Nanchang 330045, P.R. China; \\ e-mail: zengjupingjxau@163.com; liuxp@eyou.com \\ ${ }^{2}$ State Key Laboratory of Integrated Management of Pest Insects and Rodents, Institute of Zoology, Chinese Academy of Sciences, \\ Beijing 100101, P.R. China \\ ${ }^{3}$ Plant Protection and Quarantine Station, Hunan Province Agricultural Department, Changsha 410005, P.R. China; \\ e-mail: wanghaohan2005@163.com
}

Key words. Lepidoptera, Lasiocampidae, Dendrolimus punctatus, photoperiod, critical daylength (CDL), diapause development, termination, cost of diapause

\begin{abstract}
Larvae of Dendrolimus punctatus overwinter in diapause. In the Yangtze River Region, this species is multivoltine at altitudes below $400 \mathrm{~m}$ and univoltine above $700 \mathrm{~m}$ a.s.l. The photoperiodic response of the univoltine population, investigated at five day lengths $(11.5,12.5,13.5,14.5$ and $15.5 \mathrm{~h})$ at $27+1{ }^{\circ} \mathrm{C}$, indicates that D. punctatus is a long-day species. Diapause was induced in $95-100 \%$ of the individuals by three short photophases $(11.5-13.5 \mathrm{~h})$, while diapause incidence decreased steeply with increase in day length down to $10 \%$ at $15.5 \mathrm{~h}$. The critical daylength (CDL = day length resulting in a $50 \%$ incidence of diapause) is $14.6 \mathrm{~h}$. When induced by critical or longer photophases (14.5 and $15.5 \mathrm{~h}$ ), diapause terminated spontaneously, without any change in photoperiod or temperature. Diapause induced at shorter photophases was more intense and not terminated without activation by diapause averting conditions. Larvae in diapause lived for up to $190 \mathrm{~d}$ when kept under a $11.5 \mathrm{~h}$ photophase during which they remained sensitive to the photoperiodic signal. In transfer experiments, diapause was terminated after an increase in photoperiod, even if it was within the range of diapause inducing photoperiods: from $11.5 \mathrm{~h}$ to $13.5 \mathrm{~h}$. This study revealed that the univoltine hill dwelling population of $D$. punctatus undergoes a facultative diapause. Although potentially multivoltine they are univoltine because of the low temperatures at that altitude.
\end{abstract}

\section{INTRODUCTION}

Photoperiod is the most important cue initiating diapause in insects (Danilevsky et al., 1970; Tauber et al., 1986; Bradshaw \& Holzapfel, 2007) and there are two major types of photoperiodic response, a long-day response in which diapause is induced by short photoperiods and a short-day response in which diapause is induced by long photoperiods (Beck, 1980; Tauber et al., 1986). The photoperiodic response of many insects varies geographically and is genetically determined (Danks, 1987; Bradshaw \& Holzapfel, 2007), which is expressed in terms of variation in the critical photoperiod (day length for a $50 \%$ diapause response). Insect diapause is not a simple arrest of morphological development (Tauber et al., 1986; Danks, 1987; Saunders et al., 2002), but a dynamic process of diapause development (Tauber et al., 1986; Danks, 1987; Hodek \& Hodková, 1988; Hodek, 1996, 2002; Denlinger, 2002; Koštál, 2006; Ragland et al., 2009), consisting of several successive phases, such as, maintenance, termination etc. (Tauber et al., 1986; Koštál, 2006). In some insects, responsiveness to photoperiod may diminish gradually during diapause development, however, this sensitivity may persist throughout diapause and is an important diapausemaintaining factor in some insects. In these latter insects a specific photoperiodic condition is required before diapause terminates (Tauber et al., 1986). However, our understanding of how diapause ends (termination) is still very incomplete (Koštál, 2006) and the details of the processes that occur during diapause development poorly known (Hodek, 2002). Therefore, further research on the photoperiodic termination of diapause in insects is needed.

The pine caterpillar Dendrolimus punctatus is a major pest of pine forest consisting of Pinus massoniana. Outbreaks of this species are frequently recorded and often destroy the agro-forestry systems in China (Chen, 1990). It has a broad distribution ranging from $20^{\circ} \mathrm{N}$ to $34^{\circ} \mathrm{N}$ (Hou, 1987) and a variable life history. For instance, the number of generations per year decreases with increase in latitude, from four or five generations in southern China, decreasing to two generations in northern China (Hou, 1987). In the region of the Yangtze River (around latitude $30^{\circ} \mathrm{N}$ ), two or three generations are produced per year at low altitudes (below $400 \mathrm{~m}$ ) (Hou, 1987), but only one at high altitudes (above $700 \mathrm{~m}$ ) (Chen et al., 1992). D. punctatus enters larval diapause mostly during the third or fourth instar (Hou, 1987; Li \& Gia, 1991; Huang et al., 2005), mainly in response to short day lengths (Li \& Gia, 1991; Huang et al., 2005). In the region of the Yangtze River, the multivoltine populations enter diapause mostly 
in late summer or early autumn (Hou, 1987) and have a CDL of about 13.5 h (Li \& Gia, 1991; Huang et al., 2005). However, the univoltine populations enter diapause earlier (e.g. in July, Chen et al., 1992) and thus we assume their CDL is "longer". But there are no studies on the photoperiodic response of individuals from univoltine populations and whether they have a "longer" CDL is unknown. Moreover, previous studies on this moth were mainly on photoperiodic induction (Li \& Gia, 1991; Li et al., 1994, 1995; Huang et al., 2005) or coldhardiness of larvae in diapause (Han et al., 2005, 2008; Zeng et al., 2008), but not on the photoperiodic regulation of diapause development, including diapause intensity and post-diapause development. The present study analyzes the photoperiodic response of individuals from a univoltine population of $D$. punctatus in terms of the above diapause parameters. In addition, we also compared some life history traits of non-diapause and diapause generations.

\section{MATERIALS AND METHODS}

\section{Insect culture}

The cocoons of D. punctatus were collected in a forest of masson pine, Pinus massoniana, at altitudes between 700 and $800 \mathrm{~m}$ in Suining County $\left(26.35^{\circ} \mathrm{N}, 110.09^{\circ} \mathrm{E}\right)$, Hunan Province, China in June 2007. This species completes only one generation per year and the early larval instars mostly occur in July (Chen et al., 1992), which is the hottest month at these altitudes with a mean air temperature of $27 \pm 1^{\circ} \mathrm{C}$. The cocoons collected were transferred to insect cages $(60 \times 60 \times 60 \mathrm{~cm})$ and the adults that emerged were mated at $27 \pm 1^{\circ} \mathrm{C}$ and a photoperiod of $15.5 \mathrm{~L}$ : 8.5D. In the experiments, newly-laid eggs from mated females were each transferred and kept individually in a glass tube (dia. $5 \mathrm{~cm}$, length $20 \mathrm{~cm}$ ) sealed with a ball of cotton and the hatchling larvae reared at $27 \pm 1{ }^{\circ} \mathrm{C}$ under different photoperiods. Data were recorded daily when fresh needles of masson pine were also provided.

The photoperiodic experiments were conducted in illuminated chambers (LRH-250-GS) equipped with eight fluorescent $30 \mathrm{~W}$ tubes (light intensity 800-1000 lux) controlled by electric timers. In special cases the scotophase was also controlled manually by enclosing the rearing tubes in opaque hoods.

\section{Diapause induction and identification}

To induce diapause the newly-laid eggs were kept at $27 \pm 1{ }^{\circ} \mathrm{C}$ under one of five photoperiods: $11.5 \mathrm{~L}: 12.5 \mathrm{D}, 12.5 \mathrm{~L}: 11.5 \mathrm{D}$, $13.5 \mathrm{~L}: 10.5 \mathrm{D}, 14.5 \mathrm{~L}: 9.5 \mathrm{D}$ or $15.5 \mathrm{~L}: 8.5 \mathrm{D}$. Following the method of Li \& Gia $(1989,1991)$, the larvae that were small and of a yellow colour on the 30th day, which corresponds to the third and fourth instar, were categorized as in diapause. They did not move and rarely fed on the needles. By contrast, those that were not in diapause were slightly-black in colour and fed actively and continuously on the needles. They grew fast and pupated before the 50th day.

\section{Diapause development and post-diapause development}

To determine the influence of photoperiod on diapause intensity, maintenance and termination, 60 day old larvae that were in diapause were either kept at the photophases $(11.5 \mathrm{~h}, 12.5 \mathrm{~h}$, $13.5 \mathrm{~h}, 14.5 \mathrm{~h}$ or $15.5 \mathrm{~h}$ ) they were reared at, or transferred to another photophase, $13.5 \mathrm{~h}$ or $15.5 \mathrm{~h}$, which were indicated as the transferred treatments of $11.5 \mathrm{~h} \rightarrow 13.5 \mathrm{~h}, 11.5 \mathrm{~h} \rightarrow 15.5 \mathrm{~h}, 12.5$ $\mathrm{h} \rightarrow 13.5 \mathrm{~h}, 12.5 \mathrm{~h} \rightarrow 15.5 \mathrm{~h}$ or $13.5 \mathrm{~h} \rightarrow 15.5 \mathrm{~h}$.
The larval morphology (body-colour) and behaviour (moulting, feeding etc.), were recorded daily, as were the dates of pupation and adult emergence. In these experiments, those larvae that did not show a change in morphology and behaviour were considered to be in diapause and those that showed significant changes in morphology and behaviour (e.g. a slightly-black body colour, moulted and resumed active and continuous feeding on needles) were identified as post-diapause larvae. In subsequent observations, these larvae pupated, usually after moulting three or four times.

Furthermore, we weighed three-day old non-diapause or diapause pupae, using an electronic balance (sensitivity: $0.1 \mathrm{mg}$, Sartorius, R200 D.A.G., Göttingen, Germany), and determined the life-span of the adults. In each experimental regime, 30 to 218 eggs were used, and all experiments were terminated when the last adult died.

\section{Statistical analysis}

One-way analysis of variance (ANOVA) was used to analyze the data with $\mathrm{P}<0.05$, and Tukey's Honest Significant Difference test for multiple comparisons. Statistical analyses were conducted using SPSS 13.0 software.

\section{RESULTS}

\section{Photoperiodic response of the univoltine population of D. punctatus reared at $27 \pm 1^{\circ} \mathrm{C}$}

The photoperiodic response of the univoltine population reared under five different day lengths, $11.5 \mathrm{~h}, 12.5$ $\mathrm{h}, 13.5 \mathrm{~h}, 14.5 \mathrm{~h}$ and $15.5 \mathrm{~h}$ were recorded (Fig. 1). The response curve was of the long-day type. From the curve, the CDL was estimated as $14.6 \mathrm{~h}$. Diapause incidence of nearly $100 \%$ was induced by three short day lengths, $11.5,12.5$ and $13.5 \mathrm{~h}$; then the incidence steeply declined with increase in day length. The lowest incidence (10\%) was recorded at the longest day-length (15.5 h) used (Fig. 1).

\section{Influence of photoperiod on the intensity, maintenance and termination of diapause in $D$. punctatus}

The 60 day-old larvae that had been in diapause were kept under one of five diapause inducing photophases (11.5 h, 12.5 h, 13.5 h, 14.5 h or 15.5 h) or manually transferred to a longer photophase, $13.5 \mathrm{~h}$ or $15.5 \mathrm{~h}$ (see Fig. 2 for details). Fig. 2 shows that the intensity of dia-

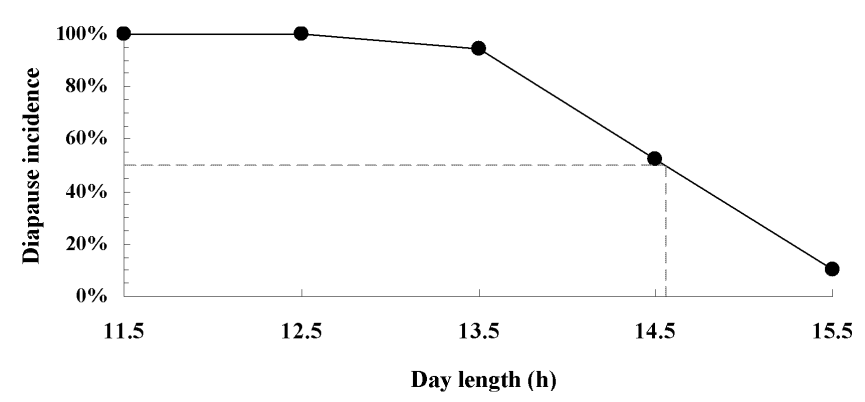

Fig. 1. Percentage incidence of diapause of individuals from the univoltine population (Suining, $700-800 \mathrm{~m}$ a.s.1.) of $D$. punctatus recorded at five different photoperiods, $11.5 \mathrm{~L}: 12.5 \mathrm{D}$ $(\mathrm{n}=167), 12.5 \mathrm{~L}: 11.5 \mathrm{D}(\mathrm{n}=218), 13.5 \mathrm{~L}: 10.5 \mathrm{D}(\mathrm{n}=127)$, $14.5 \mathrm{~L}: 9.5 \mathrm{D}(\mathrm{n}=136)$ and $15.5 \mathrm{~L}: 8.5 \mathrm{D}(\mathrm{n}=120)$ and a constant temperature of $27 \pm 1^{\circ} \mathrm{C}$. 


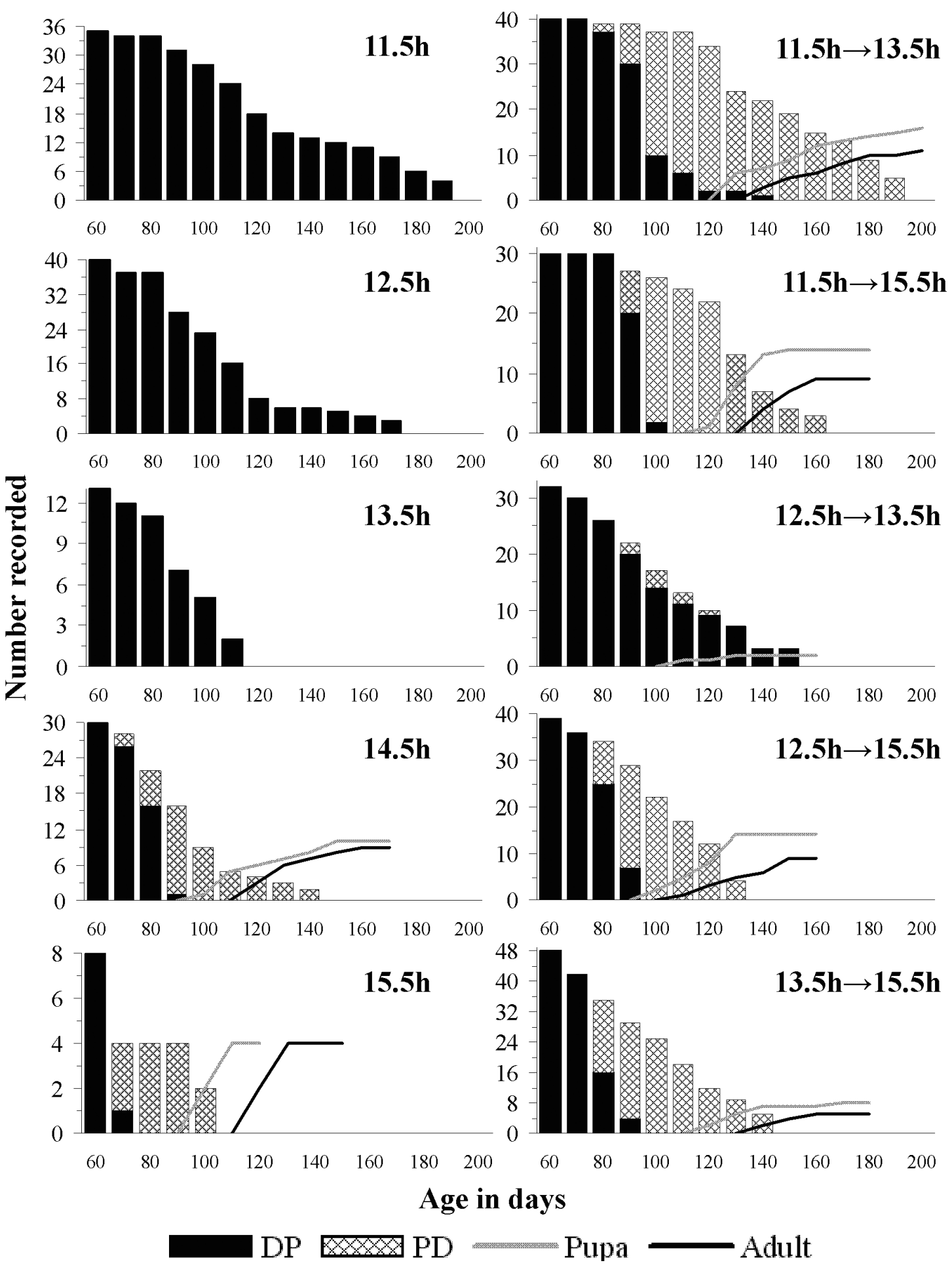

Fig. 2. The numbers of larvae of D. punctatus recorded in different stages of development when kept under diapause promoting photoperiods $(11.5 \mathrm{~h}, 12.5 \mathrm{~h}, 13.5 \mathrm{~h}, 14.5 \mathrm{~h}$ or $15.5 \mathrm{~h})$ or transferred to longer day lengths $(11.5 \mathrm{~h} \rightarrow 13.5 \mathrm{~h}, 11.5 \mathrm{~h} \rightarrow 15.5 \mathrm{~h}, 12.5 \mathrm{~h}$ $\rightarrow 13.5 \mathrm{~h}, 12.5 \mathrm{~h} \rightarrow 15.5 \mathrm{~h}$ or $13.5 \mathrm{~h} \rightarrow 15.5 \mathrm{~h}$, arrows indicate the transfer when 60 days-old). DP - diapause; PD - post-diapause development.

pause was relatively low when induced by the nearcritical photophases $14.5 \mathrm{~h}$ and $15.5 \mathrm{~h}$ as development of the larvae ceased for less than a month and then started again (Fig. 2) and the larvae pupated. However, the intensity of diapause was much greater when the larvae were reared and kept at the three short day lengths $11.5 \mathrm{~h}, 12.5$ $\mathrm{h}$ and $13.5 \mathrm{~h}$. These larvae eventually died if kept in these diapause inducing conditions (Fig. 2), with those kept in the $13.5 \mathrm{~h}$ photophase treatment dying first (within $110 \mathrm{~d}$ ) and those in the $12.5 \mathrm{~h}$ and $11.5 \mathrm{~h}$ photophase treatments surviving longer, up to $170 \mathrm{~d}$ and $190 \mathrm{~d}$, respectively (Fig. 2).

The results of the four photophase-transfer treatments presented in Fig. $2(11.5 \mathrm{~h} \rightarrow 13.5 \mathrm{~h}, 11.5 \mathrm{~h} \rightarrow 15.5 \mathrm{~h}$, 


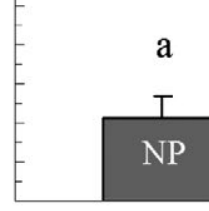

14. $5 \mathrm{~h}$

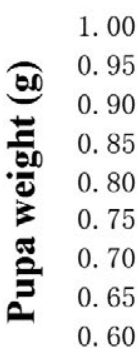

60

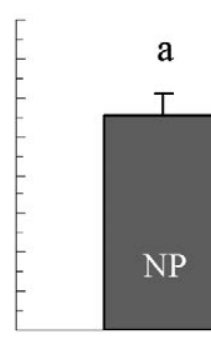

$15.5 \mathrm{~h}$

11. $5 \mathrm{~h} \rightarrow 15.5 \mathrm{~h}$

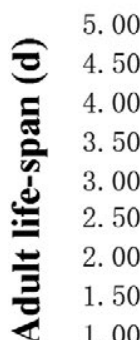

1. 00

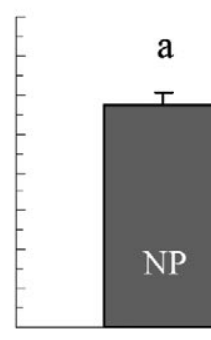

$15.5 \mathrm{~h}$
Fig. 3. Comparisons of the pupal weights and adult life-spans of individuals that did not diapause (NP) and those that did (DP) kept under a photoperiod of $14.5 \mathrm{~h}$ or $15.5 \mathrm{~h}$ or transferred from a $11.5 \mathrm{~h} \rightarrow 15.5 \mathrm{~h}$ photoperiod (see Fig. 2 for details).

$12.5 \mathrm{~h} \rightarrow 15.5 \mathrm{~h}$ and $13.5 \mathrm{~h} \rightarrow 15.5 \mathrm{~h}$, but not $12.5 \mathrm{~h} \rightarrow$ $13.5 \mathrm{~h})$ show that larvae in diapause can respond to an increase in day length by awaking from diapause and resuming growth. We calculated the time from the day on which the photoperiod was increased to the day on which the post-diapause larvae showed signs of a slight darkening in the colour of the body and of actively feeding on needles and expressed this in terms of days in Table 1. This revealed that diapause was terminated after different periods of time in these four transfer treatments $\left(\mathrm{F}_{3,99}=\right.$ 44.937, $\mathrm{P}<0.001)$. The shortest period $(22.4 \mathrm{~d})$ was recorded in the $13.5 \mathrm{~h} \rightarrow 15.5 \mathrm{~h}$ photophase treatment and longer periods of $37 \mathrm{~d}$ and $38 \mathrm{~d}$, respectively, in the 11.5 $\mathrm{h} \rightarrow 13.5 \mathrm{~h}$ and $11.5 \mathrm{~h} \rightarrow 15.5 \mathrm{~h}$ treatments, i.e. a more intense diapause was induced by the shorter $11.5 \mathrm{~h}$ day length (Fig. 2).

The time taken by larvae after awaking from diapause to complete their development and pupate is given in Table 1. It was significantly different in the above four transfers between photophases $\left(\mathrm{F}_{3,48}=10.787, P<0.001\right)$. The longest was recorded in $11.5 \mathrm{~h} \rightarrow 13.5 \mathrm{~h}$ treatment, with the larvae requiring $92.5 \mathrm{~d}$ to complete their development and pupate when reared under the relatively short $13.5 \mathrm{~h}$ photophase.

Comparisons of pupal weights and adult life-spans of individuals of $D$. punctatus, which as larvae did not or did enter diapause

The cost of diapause was measured in terms of the pupal weight and adult life-span of individuals that as larvae that did not enter diapause (NP) and those that did (DP) and the results are presented in Fig. 3. The pupal weights of the NP and DP individuals reared under $14.5 \mathrm{~h}$ and $15.5 \mathrm{~h}$ photophases did not differ significantly (respectively $\mathrm{F}_{1,24}=0.074, \mathrm{P}=0.788$ and $\mathrm{F}_{1,59}=0.151, \mathrm{P}$ $=0.699$ ). However, the adult life-span of the DP individuals was significantly shorter in the $15.5 \mathrm{~h}$ treatment $\left(F_{1,53}=9.025, P=0.004\right)$ (see Fig. 3).

\section{DISCUSSION}

\section{Response of individuals from multivoltine and univoltine populations of $\boldsymbol{D}$. punctatus to photoperiod}

Our results confirm earlier findings that the pine caterpillar D. punctatus is a long-day animal (Hou, 1987; Li \& Gia, 1991; Huang et al., 2005). Beck (1980) says that long-day insects only enter diapause when days are short and consistently reproduce, grow and develop under the long-day conditions prevailing in late spring and early summer (Tauber et al., 1986). As for D. punctatus, it usually defoliates forests of masson pine from May to July in the Yangtze River region (Hou, 1987; Chen, 1990). The natural day-length at that time is $14.0 \mathrm{~h}$ or above, longer than either the CDL value of $13.3 \mathrm{~h}$ cited by Huang et al. (2005) or that of $13.5 \mathrm{~h}$ by Li \& Gia (1991), which are the minimum day lengths required for fast growth and reproduction of this pest. However, the CDL varies with latitude in many species, mostly greater in the north than in the south (Danks, 1987). In Daphnia pulex, for example, its CDL increases from $13 \mathrm{~h}$ at $45^{\circ} \mathrm{N}$ to $22 \mathrm{~h}$ at $71^{\circ} \mathrm{N}$ (Stross, 1971). D. punctatus also has a broad distribution, from $20^{\circ}$ to $34^{\circ} \mathrm{N}$ latitude (Hou, 1987), and Gia (1993) indicates that its CDLs increase from $13.0 \mathrm{~h}$ at $26.0^{\circ} \mathrm{N}$ to $13.5 \mathrm{~h}$ at $30.0^{\circ} \mathrm{N}$, with an increase of about one hour for

TABLE 1. Time required by D. punctatus for diapause termination and pupation when subjected to one of four different types of increase in photophase. Lower case letters indicate significant differences $(\mathrm{P}<0.05)$, see Fig. 2 for details.

\begin{tabular}{ccc}
\hline Photophase changes (sample) & Time to termination (days; mean \pm SE) & Time to pupation (days; mean \pm SE) \\
\hline $11.5 \rightarrow 13.5 \mathrm{~h} \mathrm{(40)}$ & $38.4 \pm 1.5 \mathrm{a}$ & $92.5 \pm 5.8 \mathrm{a}$ \\
$11.5 \rightarrow 15.5 \mathrm{~h}(30)$ & $37.1 \pm 0.9 \mathrm{a}$ & $74.3 \pm 2.0 \mathrm{~b}$ \\
$12.5 \rightarrow 15.5 \mathrm{~h}(39)$ & $25.9 \pm 1.1 \mathrm{~b}$ & $59.3 \pm 3.0 \mathrm{~b}$ \\
$13.5 \rightarrow 15.5 \mathrm{~h}(48)$ & $22.4 \pm 0.9 \mathrm{c}$ & $75.0 \pm 5.7 \mathrm{~b}$ \\
\hline
\end{tabular}


every $8^{\circ}$ latitude. A similar increase of one hour per $5.4^{\circ}$ latitude is reported for Wyeomyia smithii (Bradshaw, 1976; Bradshaw \& Lounibos, 1977) and one hour per $7^{\circ}$ latitude for Phyllonorycter ringoniella (Ujiye, 1985). As the CDL increases toward the north, an insect can complete fewer generations per annum in the north than the south, e.g., in D. punctatus it declines from 5 to 2 (Hou, 1987).

Furthermore, there is also an increase in CDL with increase in altitude (Danks, 1987; Bradshaw \& Holzapfel, 2007), which is confirmed by our results. In the region of the Yangtze River, the CDL is relatively "long", $14.6 \mathrm{~h}$, in the univoltine population of D. punctatus that occurs at an altitude of $700 \mathrm{~m}$ or above (Chen et al., 1992), compared to the $13.3 \mathrm{~h}$ or $13.5 \mathrm{~h}$ CDLs of multivoltine populations that occur at altitudes below $400 \mathrm{~m}$, and increases about one hour per $400 \mathrm{~m}$ increase in altitude in this region. The growing season for all organisms is shorter at high than at low altitudes and they are more likely to enter winter diapause earlier at high altitudes (Hodkinson, 2005). This study provides support for the day length triggering diapause being significantly longer for high than low altitude populations of the same species. Field observations indicate that highland populations of $D$. punctatus mostly enter diapause early in mid-July (Chen et al., 1992) when the day length is $14.5 \mathrm{~h}$ or so and diapause is triggered one month or earlier than in lowland populations, where they mostly enter diapause in late August or September. In summer, the temperature decreases rapidly after July in the high regions of Suining, e.g, in 2007 the average air temperature decreased from $27.6^{\circ} \mathrm{C}$ in July down to $26.8^{\circ} \mathrm{C}$ in August and to $22.0^{\circ} \mathrm{C}$ in September. At these temperatures, the larvae enter winter diapause sooner, which synchronizes their life cycle with the highland season; this represents an important adaptive benefit for this species.

\section{Diapause intensity, maintenance and termination under constant photoperiod or a change of photoperiod in $D$. punctatus}

Diapause intensity is measured in terms of the duration of the developmental arrest (diapause) at a given moment and under given environmental conditions (Vinogradova, 1974). Results of this study indicate that diapause intensity in D. punctatus depends on the length of the inducing photoperiod, whereas in other insects the response is all or none (Danks, 1987), such as in the blow fly Lucilia caesar (Ring, 1968) and butterfly Pieris brassicae (Tyshchenko \& Goryshin, 1979). A relatively weak diapause (low intensity) was induced by near-critical photoperiods (photophase $14.5 \mathrm{~h}$ and $15.5 \mathrm{~h}$ ) and terminated spontaneously (Fig. 2), as occurs in many other insects and mites kept under constant photoperiod or temperature conditions in a laboratory (Danks, 1987; Koštál, 2006). Larvae in intense diapause, induced by short photoperiods (photophases $11.5 \mathrm{~h}, 12.5 \mathrm{~h}$ and $13.5 \mathrm{~h}$ ), did not resume development and eventually died (Fig. 2) if not exposed to long day conditions. This also occurs in Diprion pini, as the eonymphs in diapause will not pupate and eventually die if not exposed to long days (Eichhorn, 1977). We also found that larvae in deep diapause kept under very short day conditions (e.g. at $11.5 \mathrm{~h}$ ) survived for longer than those kept at $13.5 \mathrm{~h}$. This indicates that larvae in deep diapause may have a lower metabolic rate, which enables them to survive longer.

Photoperiod is one of two major factors that maintain diapause (Tauber et al., 1986). However, in our study only three short photophases (11.5 h, $12.5 \mathrm{~h}$ and $13.5 \mathrm{~h}$ ) maintained diapause in D. punctatus (see Fig. 2). Many species gradually become less sensitive to photoperiod during diapause development, e.g. the Odonate Lestes eurinus (Lutz, 1968), linden bug Pyrrhocoris apterus (Hodek, 1971) and flesh fly Sarcophaga bullata (Denlinger, 1972). D. punctatus, however, remained sensitive to photoperiod throughout diapause. In the transfer experiments, for instance, diapause was terminated when they were transferred from a short $(11.5 \mathrm{~h})$ inducing photophase to a "longer" photophase (e.g. $13.5 \mathrm{~h}$ or $15.5 \mathrm{~h}$ ). Here, the "short" photophase of $13.5 \mathrm{~h}$ (a diapauseinducing and maintaining photophase) terminated diapause evidently due to the $2 \mathrm{~h}$ lengthening of the photophase (e.g. $11.5 \mathrm{~h} \rightarrow 13.5 \mathrm{~h}$ in Fig. 2). This indicates that the thresholds photoperiods critical for diapause induction and termination usually differ (Danks, 1987). For instance, in the bug Pyrrhocoris apterus, the critical photoperiod for the end of diapause is one hour longer than that for induction (Saunders, 1983). And in the lacewing Meleoma signoretti, the difference is about two hours (Tauber et al., 1986). In addition, a change in the length of the short photoperiods, which induce diapause, can terminate diapause development in this moth, as in some other insects (see Danks, 1987, pp. 143-144). For example, eonymphs of the sawfly Neodiprion pini will emerge if transferred from short days to somewhat longer days, which normally induce diapause (Eichhorn, 1977).

In Pectinophora gossypiella daily photophases of 14-16 h terminate diapause more rapidly than 8- or 12-h photophases (Watson et al., 1973). In addition, the time taken to terminate diapause may be also dependent on the diapause-inducing conditions. For instance, in D. punctatus, it took longer to terminate diapause induced by the "short" short-photophase of $11.5 \mathrm{~h}$ than that induced by the "long" short-photophase of $13.5 \mathrm{~h}$ (see Table 1). This again suggests that deep diapause takes longer to terminate. However, it is worth mentioning that post-diapause development is more dependent on current photoperiods than on the diapause inducing photoperiods (see Table 1).

In addition to the effect of photoperiod diapause can be terminated by high temperature. For instance, diapause in Teleogryllus commodus persists for long periods (60-80 days) at $20^{\circ} \mathrm{C}$, but is terminated very quickly after a brief exposure to high temperatures (e.g. $30^{\circ} \mathrm{C}$ ) (Masaki et al., 1979).

In insects, the individuals that diapause require greater energy reserves for maintenance than those that do not. This indicates there is a cost associated with diapause that might affect other life-history traits. For example, in Acanthoscelides pallidipennis, the fecundity and body size of adults that spent some time in diapause during 
their development are less than those that did not diapause (Sadakiyo \& Ishihara, 2012). Our results also indicate there is a cost as those individuals of D. punctatus that entered diapause had a shorter adult life-span than those that did not (see Fig. 3). A similar situation occurs in Leptinotarsa decemlineata (Jansson et al., 1989) and Busseola fusca (Gebre-Amlaka, 1989).

In conclusion, our results reveal that a single environmental factor, photoperiod, can greatly influence the expression of diapause development. Larval diapause was relatively deep when induced by short photoperiods and can be maintained by these inducing photoperiods. However, a relatively weak diapause was induced by nearcritical or long photoperiods and is terminated spontaneously. Changes in photoperiod accelerated diapause development and decreased the intensity gradually or rapidly. This supports the possibility that there are "multiple pathways of diapause development in every individual (Hodek, 2002).'

ACKNOWLEDGEMENTS. We gratefully thank I. Hodek, Institute of Entomology, AS CR, who commented on the most recent manuscript. We also thank F. Ge, Institute of Zoology, CAS, and F.S. Xue, Institute of Entomology, Jiangxi Agricultural University, for their valuable suggestions for improving a previous manuscript. The funds for this study came from a Key Program of National Natural Science Foundation of China (30330490) and partly the Central Finance Special Fund of China (STSN-04-04).

\section{REFERENCES}

Beck S.D. 1980: Insect Photoperiodism, 2nd ed. Academic Press, New York, 387 pp.

BRADSHAW W.E. 1976: Geography of photoperiodic response in diapausing mosquito. - Nature 262: 384-386.

Bradshaw W.E. \& Holzapfel C.M. 2007: Evolution of animal photoperiodism. - Annu. Rev. Ecol. Evol. Syst. 38: 1-25.

BRADSHAW W.E. \& LounibOS L.P. 1977: Evolution of dormancy and its photoperiodic control in pitcher-plant mosquitoes. Evolution 31: 546-567.

CHEN C.J. 1990: Integrated Management of Pine Caterpillars in China. China Forestry Publishing House, Beijing, 401 pp. [in Chinese].

Chen L.C., Luo M.L., Zhu W. \& Zhu Q.L. 1992: Investigation in a univoltine species of the pine caterpillar in Hunan Province. - Forest Dis. Pest Rep. 3: 22-23 [in Chinese].

Danilevsky A.S., Goryshin N.I. \& Tyshchenko V.P. 1970: Biological rhythms in terrestrial arthropods. - Annu. Rev. Entomol. 15: 201-244.

DANKs H.V. 1987: Insect Dormancy: An Ecological Perspective. Biological Survey of Canada (Terrestrial, Arthropods), Ottawa, 439 pp.

Denlinger D.L. 1972: Seasonal phenology of diapause in the flesh fly Sarcophaga bullata. - Ann. Entomol. Soc. Am. 65: 410-414.

Denlinger D.L. 2002: Regulation of diapause. - Annu. Rev. Entomol. 47: 93-122.

EICHHORN O. 1977: Autökologische Untersuchungen an Populationen der gemeinen Kiefern-Buschhornblattwespe Diprion pini L. (Hym.: Diprionidae). III. Laborzuchten. - Z. Angew. Entomol. 84: 264-282.

GiA F.Y. 1993: Geographical variation of photoperiodic response in the pine caterpillar. - Forest Res. 6: 52-57 [in Chinese with English abstr.].
Gebre-Amlaka A. 1989: Phenology and fecundity of maize stalk borer Busseola fusca (Fuller) in Awassa, Southern Ethiopia. - Int. J. Trop. Insect Sci. 10: 131-137.

Han R.D., Ge F., Yardim E.N. \& He Z. 2005: The effect of low temperatures on diapause and non-diapause larvae of the pine caterpillar, Dendrolimus tabulaeformis Tsai et Liu (Lepidoptera: Lasiocampidae). - Jap. J. Appl. Entomol. Zool. 40: 429-435.

Han R.D., Gan Y.L., Kong X.H. \& Ge F. 2008: Physiological and endocrine differences between diapausing and nondiapausing larvae of the pine caterpillar Dendrolimus tabulaeformis (Lepidoptera, Lasiocampidae). - Zool. Stud. 47: 96-102.

HODEK I. 1971: Sensitivity of larvae to photoperiods controlling the adult diapause of two insects. - J. Insect Physiol. 17: 205-216.

HodeK I. 1996: Diapause development, diapause termination and the end of diapause. - Eur. J. Entomol. 93: 475-487.

HoDeK I. 2002: Controversial aspects of diapause development. - Eur. J. Entomol. 99: 163-173.

Hodek I. \& Hodková M. 1988: Multiple role of temperature during insect diapause: a review. - Entomol. Exp. Appl. 49: $153-165$.

HoDKINSON I.D. 2005: Terrestrial insects along elevation gradients: species and community responses to altitude. - Biol. Rev. 80: 489-513.

Hou T.Q. 1987: The Pine Caterpillars in China. Science Press, Beijing, 311pp. [in Chinese].

Huang L.L., Xue F.S., Wand G.H., Han R.D. \& Ge F. 2005: Photoperiodic response of diapause induction in the pine caterpillar, Dendrolimus punctatus. - Entomol. Exp. Appl. 117: 127-133.

Jansson R.K., Zitzman A.E. \& Lashomb J.H. 1989: Effects of food plant and diapause on adult survival and fecundity of Colorado potato beetle (Coleoptera: Chrysomelidae). - Environ. Entomol. 18: 291-297.

KošTÁL V. 2006: Eco-physiological phases of insect diapause. - J. Insect Physiol. 52: 113-127.

Li Z.L. \& GiA F.Y. 1989: Photoperiodic reaction of the pine caterpillar Dendrolimus tabulaeformis Tsai et Liu. - Acta Entomol. Sin. 32: 410-417 [in Chinese with English abstr.].

Li Z.L. \& GiA F.Y. 1991: The photoperiodic reaction (PhPR) of the pine caterpillar: studies on the mechanism of the second generation differentiation. - Forest Res. 4: 409-413 [in Chinese with English abstr.].

Li Z.L., Gia F.Y., Hou W.W., He Z., Wen Z.Z. \& Wen X.S. 1994: Photoperiodical reaction of the pine caterpillar Dendrolimus punctatus (Walker). - Acta Entomol. Sin. 37: 31-37 [in Chinese with English abstr.].

Li Z.L., Gia F.Y., He Z. \& Hou W.W. 1995: The impact of thermoperiodism on the pine caterpillar in photoperiodic response. - Forest Res. 8: 413-416 [in Chinese with English abstr.].

LuTz P.E. 1968: Effects of temperature and photoperiod on larval development in Lestes eurinus (Odonate: Lestidae). Ecology 49: 637-644.

Masaki S., Ando Y. \& Watanabe A. 1979: High temperature and diapause termination in the eggs of Teleogryllus commodus (Orthoptera: Gryllidae). - Kontyu 47: 493-504.

Ragland G.J., Fuller J., Feder J.L. \& Hahn D.A. 2009: Biphasic metabolic rate trajectory of pupal diapause termination and post-diapause development in a tephritid fly. $-J$. Insect Physiol. 55: 344-350.

RiNG R.A. 1968: Termination of diapause in the larva of Lucilia caesar L. (Diptera: Calliphoridae). - Can. J. Zool. 46: 335-344. 
SADAKIYo S. \& IshiHARA M. 2012: Cost of diapause on lifehistory traits under restricted resources in multivoltine Bruchid Acanthoscelides pallidipennis (Coleoptera: Bruchidae). - Ann. Entomol. Soc. Am. 105: 422-426.

SAUNDERS D.S. 1983: A diapause induction-termination asymmetry in the photoperiodic responses of the linden bug, Pyrrhocoris apterus and an effect of near-critical photoperiods on development. - J. Insect Physiol. 29: 399-405.

Saunders D.S., Steel C.G.H., Vafopoulou X. \& Lewis R.D. 2002: Insect Clocks. Elsevier Science, Amsterdam, 576 pp.

Stross R.G. 1971: Photoperiodism and diapause in Daphnia: a strategy for all seasons. - Trans. Am. Math. Soc. 90: 110-112.

TAuber M.J., TAuber C.A. \& MasaKi S. 1986: Seasonal Adaptations of Insects. Oxford University Press, Oxford, $411 \mathrm{pp}$.

Tyshchenko G.F. \& Goryshin N.I. 1979: The effect of photothermal conditions on the diapause (induction and depth) in Pieris brassicae (Lepidoptera, Pieridae). - Entomol. Obozr.
58: 481-489 [in Russian, translation in Entomol. Rev. 58: 1-9.]

Uлтуе T. 1985: Studies on the diapause of the apple leaf miner, Phyllonorycter ringoniella (Matsumura) (Lepidoptera: Gracillariidae) III. The geographical variation in the photoperiodic responses on the induction of diapause. - Jap. J. Appl. Entomol. Zool. 29: 198-202 [in Japanese with English abstr.].

VINOGRadova Ye.B. 1974: The pattern of reactivation of diapausing larvae in the blowfly, Calliphora vicina. - J. Insect Physiol. 20: 2487-2496.

Watson T.F., LindSEY M.L. \& Slosser J.E. 1973: Effect of temperature, moisture, and photoperiod on termination of diapause in the Pink Bollworm. - Environ. Entomol. 2: 967-970.

Zeng J.P., Ge F., Su J.W. \& Wang Y. 2008: The effect of temperature on the diapause and coldhardiness of Dendrolimus tabulaeformis (Lepidoptera, Lasiocampidae). - Eur. J. Entomol. 105: 599-606.

Received October 3, 2011; revised and accepted September 14, 2012 